Neste artigo, procura-se rever alguns "preconceitos escolásticos" - preconceitos que envolvem aqueles que participam de determinada escola, neste caso, a escola criada a partir dos ensinamentos de Lacan - e suas implicações na clínica de bebês e crianças pequenas. Para tanto, atravessamos algumas questôes: A criança nasce como uma página em branco? O que é desenvolvimento? A partir de quando podemos supor a existência do inconsciente? Por que é importante para o psicanalista o que diz respeito ao orgânico $\mathrm{e}$ ao desenvolvimento? A interdisciplina é entendida como fundamental, assim como a clareza por parte do psicanalista, das contribuições e limites da psicanálise na referida clínica. Bebês - Interdisciplina Psicanálise

\section{WHAT IS ABOUT?}

Psicanáliseln this paper, we try to review some "scholastic prejudices" which includes those who participate of a specific theoretical school, in this case, the school that follows

Lacan's ideas - and its implications on the clinic of babies and of litlle children. We discuss some questions: Is the child born as a white paper? What is development? From when on can we suppose the existence of the insconscious? Why are psychoanalists concerned with the organic? The interdiscipline is bere understood as fundamental.

Babies - interdiscipline Psychoanalysis

\section{DE QUE \\ SE TRATA... UMA CRIANÇA? ${ }^{1}$}

\author{
Elsa Coriat \\ Tradução: Daniela Teperman
}

(

analista lacaniano que queira avançar na formalização da psicanálise de crianças terá que desembaraçar-se de uma série de preconceitos escolásticos.

Este pequeno parágrafo me ocorreu em um momento qualquer, preocupada com o convite recebido para participar de um Congresso e tentando situar qual seria o novo ângulo que me permitiria retomar meus temas de sempre.

Estava caminhando pela rua junto com minha filha uma jovem de 16 anos - e, enquanto tentava recordar o que eu queria dizer com "escolástico", lhe perguntei:

- "Você gosta da expressão "preconceitos escolásti$\cos " ?$

-"O que quer dizer "escolástico"? perguntou-me ela.

Enquanto eu continuava tentando encontrar a resposta que me escapava, ela acrescentou:

-"Escolástico" vem de "escola"?

Neste momento... eu faria uma homenagem à língua!

A partir da momentânea ignorância das duas a respeito do significado de uma palavra, minha filha me mostrou que carregava exatamente a significação que eu

Psicanalista, membro da equipe do Centro "Lydia Coriat", de Buenos Aires. 
queria dar-lhe. Já quase não importava o que poderia encontrar no dicionário, porque até mesmo quem nada sabia sobre o tema escutava o que me interessava discutir, ou seja, os preconceitos que envolvem os que participam de determinada escola - a escola criada a partir do ensinamento de Lacan - nos dias de hoje.

Não me refiro aqui a nenhuma instituição em particular, mas ao conjunto do lacanismo em geral - reconhecendo que, nem todas as instituições, nem todos que se reconhecem ou se autodenominam "lacanianos", participam igualmente na extensão e sustentação daquilo que chamo preconceitos.

Seguindo Bachelard, chamo "preconceitos" aos "conhecimentos usuais, ao que acreditamos saber".

"Frente ao mistério do real a alma não pode, por decreto, tornar-se ingênua. (...) diante da cultura científica, o espírito jamais é jovem. É até muito velho, pois tem a idade de seus preconceitos”.

"(...) Se não houve pergunta, não pode haver conhecimento científico. No entanto, um conhecimento adquirido por um esforço científico pode declinar. A pergunta abstrata e franca se desgasta; a resposta concreta fica. (...) Com o uso, as idéias se valorizam indevidamente. Um valor em si se opõe à circulação dos valores. É um fator de inércia para o espírito".

"(...) pode-se reconhecer que a idéia científica muito familiar carrega um concreto psicológico excessivamente pesado (...) e que pouco a pouco perde seu valor de abstração, sua afiada ponta abstrata". (p. 15/19)

Vocês não sentem, às vezes, que amplos setores do lacanismo estão voltando a ocultar a afiada relha do arado freudiano com um acúmulo de enunciados, articulados formalmente entre si, mas vazios?

Se trago à tona estas questões em um encontro sobre psicanálise de crianças, é porque a pergunta que, em tantos humanos, inaugura o desejo de saber, é a pergunta sobre a origem, e as que continuam alimentando a luz das indagações são as perguntas sobre como e por que.

Que aos 4 ou 5 anos estas perguntas não cheguem a produzir mais que teorias sexuais infantis, ou que nos primórdios da humanidade tenham se satisfeito com a construção de mitos, não implica que sejam perguntas pueris ou primitivas. A própria psicanálise não haveria nascido se Freud não as houvesse formulado. São as perguntas proibidas pela religião, são as que a magia não se preocupa em formular, e são as que a psicanálise partilha com a ciência na construção da teoria.

O conceito de estrutura, por exémplo, é imprescindível à teoria e à clínica psicanalítica, mas certas maneiras de utilizá-lo - muito em voga nestes tempos pós-modernos - fazem convergir passado, presente e futuro em uma eterna sincronia, obturando as perguntas sobre a origem, assim como sobre as sucessivas transformações que vão se operando no devir, ou seja, no necessário transcorrer 
de um tempo que denominamos cronológico $^{2}$.

Há alguns anos, quando ainda não havia me formado, paralelamente ao que me ensinavam na Faculdade de Psicologia passei a fazer parte de um grupo de estudos coordenado por uma docente lacaniana. Ainda hoje the agradeço que tenha marcado como primeira leitura o capítulo VII da "Interpretação dos Sonhos", no qual Freud nos fala da primeira experiência de satisfação e do esquema do pente. No entanto, comentando esse esquema, acrescentou algo como: "há quem considere que cada bebê nasce como uma página em branco. Não leva em conta que há toda uma história que o precede, que vem de antes do seu nascimento!"

Alguém saberá quem foi o autor da idéia de que um bebê nasce como uma página em branco... Neste momento, junto com a docente, todos os do grupo rimos de semelhante absurdo, quase aliviados de que Lacan houvesse voltado a trazer à ordem do dia a descoberta freudiana do determinante da história familiar. Com tudo o que havia sido escrito, como pensar que um bebê vinha em branco?

Não muito tempo depois, comecei a trabalhar na clínica de crianças e de bebês, e continuei me perguntando por quais caminhos o bebê se converte em um sujeito desejante, até que me dei conta do pequeno e ao mesmo tempo enorme mal-entendido condensado na crítica aos que consideravam-no como uma página em branco. É certo que há toda uma história que o precede! Mas o detalhe é que essa história está escrita em outro lugar, e nào justamente no recém-nascido.

No início, o infans se limita a receber do Outro as marcas dessa história. A partir do fort-da começará a apropriarse das mesmas, brincando com elas. Enquanto é pequenino e vai construin- do a capacidade - sempre fracassada de entender a linguagem, irá escutando as histórias que são contadas na vida familiar ou recolhendo pedacinhos de anedotas, mas assim que chegar à puberdade contará com a dimensão histórica suficiente para situar-se ele mesmo como herdeiro de sua própria linhagem.

Não é a mesma coisa receber e tomar. Nào é a mesma coisa herdar e adquirir.

Em meu "Projeto de uma neurologia para psicanalistas" (Reunião Lacanoamericana de Porto Alegre), texto produzido há cinco anos, apresentei pela primeira vez a metáfora em que considerava o sistema nervoso central o papel no qual a letra ficará registrada. Obviamente, implicava em que o papel estivesse em branco até então e, com a primeira experiência de satisfação, ficasse escrito o primeiro traço mnemônico. Obviamente também, implicava em que os traços mnemônicos que continuariam a série seriam os deixados pelas sucessivas experiências.

Isto é Freud básico. Por que dar tanta importância a uma metáfora que nem sequer é minha?

Porque em minha própria resistência a apresentá-la assim - demorei vários anos - leio os preconceitos pelos quais fui tomada. E é parte de úm Freud forcluído, acusado de biologista, tomado pelas supostas necessidades do discurso cientificista da época.

Atualmente, não é que nunca se fale da primeira experiência de satisfação, ela é descrita freqüentemente, mas quase como uma simpática história infantil, proveniente da infância da psicanálise, sem nenhuma outra implicaçào prática que a de suturar com palavras um ponto cego no saber.

Enquanto eu apresentava esta primeira experiência em tais termos, ocorreu, mais que uma vez, que alguém - e 
sempre se tratava de alguém que se considerava "lacaniano"- considerasse necessário frisar: "Mas é um mito!" Como se esse mito não tivesse nada a ver com o que acontece a um bebê no real, ou como se minhas palavras, mostrando até que ponto a construção de Freud é coincidente com o que efetiva e necessariamente tem lugar na vida de qualquer bebê, violassem o que devia permanecer como puro postulado teórico.

Adianto que se estas questões não tivessem importantes implicações na clínica de crianças e de bebês, não me deteria a comentá-las. Quais são estas implicações?

Determinada maneira de entender o conceito de estrutura e de papel fundante do Outro levou a que, nas primeiras tentativas de uma clínica lacaniana de crianças, se desprezasse o trabalho com a criança e apenas se levasse em conta o Outro, encarnado nos pais. Mas ainda que o desejo do Outro seja a condição de onde provém toda escritura fundante, o que fica efetivamente escrito é a marca deixada pela experiência tal como a mesma é registrada pela criança. Se o Outro tem um papel fundante é porque é quem cria as condições nas quais a experiência se apresenta - incluindo a apresentação do objeto - mas o registro corre por conta da criança e de suas possibilidades.

$\mathrm{Na}$ "Carta 52", Freud propõe que consideremos três sistemas de inscrição: o dos signos de percepçào, o inconsciente e o pré-consciente. "Devo destacar" - diz - "que as sucessivas transcriçôes representam a obra psíquica de sucessivas épocas da vida" (Freud, 1973a, p. 3551/2).

O sistema de inscrição dos signos de percepção é, em sua origem, cronologicamente anterior ao sistema inconsciente, e nele opera exclusivamente "a asssociaçâo por simultaneidade". Logo em seguida, quando se forme o sistema
Inc., aparecerão as associações causais e poderão ficar registradas lembranças conceituais.

O que foi feito dos signos de percepção no pensamento freudiano? Até recentemente, cada vez que me detinha a olhar o esquema do pente me perguntava por que Freud se dedicou a grafar primeiro os dentes correspondentes aos traços mnemônicos e logo depois situou o inconsciente. Me perguntava: será que os traços mnemônicos não estão no Inc.? Somente depois de confrontar este esquema com a "Carta 52" pude encontrar uma resposta.

É que o inconsciente não vem dado a princípio, e nem aparece de um dia para outro, instalando-se a partir do nada. Precedendo-o, se faz necessária a inscrição, na criança-bebê, de toda uma série prévia de traços mnemônicos.

Se dizíamos que a inscrição da experiência corre por conta da criança, quais são suas possibilidades de registro? Em um primeiro momento, conta apenas com o biologicamente herdado: seus órgãos de percepção. As primeiras experiências irão deixando sua marca, seu traço mnemônico, imprimindo os signos com o que impactou como prazer ou desprazer.

Se diante do primeiro desprazer o organismo reagiu com o choro em forma reflexa, uma vez instalado o primeiro traço mnemônico do objeto desconhecido até então - que proporcionou prazer, a atividade intencional irá substituindo cada vez mais a ação reflexa e, paralelamente, irá recortando cada vez mais a realidade do mundo.

A partir de quando podemos começar a supor a existência de um inconsciente? Se o inconsciente está estruturado como uma linguagem, e se a estrutura de uma linguagem consiste em um "colar de anéis que se sela no anel de outro colar feito de anéis" (Lacan, 1985, p.481), necessita então, no míni- 
mo, a existência de suas unidades, esses elementos diferenciais últimos que são os fonemas.

Para o bebê, e desde recém-nascido, o objeto voz se encontra entre os privilegiados; pode-se supor que, como tal, fica registrado entre os traços mnemônicos do sistema de signos de percepção desde o começo. Mas uma coisa é a voz como objeto e outra a discriminação dos fonemas da língua que a voz transporta. Roman Jakobson nos informa que entre os 6 e 8 meses os bebês começam a selecionar os fonemas de sua língua materna - e os bebês nos dão provas disso. A partir disso têm a possibilidade de começar a ir registrando as seqüências fonéticas que implicam os significantes, os primeiros S2 da bateria inconsciente, bem antes também de relacioná-las com o significado convencional que lhe atribui sua língua e que se alojará no pré-consciente.

Nestes últimos parágrafos venho fazendo um breve resumo de questões que desenvolvi mais longamente em outros textos (1997), mas se volto a abordá-las é para que se perceba a importância do transcorrer do tempo, do tempo em que se produz a repetição da experiência. E também para que se perceba que, no compasso dessa experiência de repetição, vai se construindo a estrutura do aparelho psíquico.

Nos tempos prévios à emergência de um sujeito no real, o que a intervenção do Outro proporciona é a libidinização e delineamento da zona erógena, a delimitação de suas bordas de forma que terminarão recortando e fazendo cair o objeto como impossivel de voltar a encontrar. A criança começa a encarregar-se desta queda ao fazer cair o carretel do fort-da; recupera e volta a perder o objeto, mas com o barbante ao qual está atado, com os laços de presença-ausência do significante. Não deixemos de mencionar aqui que, para a clínica de crianças, é fundamental não esquecer que o pequenino precisa de carretel e barbante para começar seu jogo de elaboração significante.

Aproximadamente no tempo do fort-da se iniciará a descoberta do pai em sua função enquanto tal; em seguida, com um pouco de sorte e poucos anos mais tarde, o encontro com " $O$ objeto (que ainda se empenhava em conseguir) passará a estar definitivamente proibido.

Volto a dizer que, até aqui, venho repetindo uma série de questões, a maioria das quais vocês já conhecem. Qual é a novidade que justifica esta exposição? Talvez a novidade seja colocá-las em série. Colocá-las em série para evidenciar que todo desenvolvimento infantil implica em percorrer uma série de marcos ou pontos fundamentais que necessariamente vão se sucedendo um ao outro, em uma certa ordem, requerendo por sua vez um certo tempo. Para que cada passo seja dado, é condição necessária que tenha sido efetuado o anterior, ainda que nenhum seja condição suficiente para garantir o que virá em seguida.

Creio que isso também não é uma grande novidade: começando por Freud há muitos outros autores que se ocuparam do tema, mas as duras críticas que Lacan efetuou às muito criticáveis concepções do desenvolvimento pósfreudianas fizeram com que o próprio conceito de desenvolvimento ficasse semi-forcluído do pensamento lacaniano, com os conseguintes efeitos limitantes sobre a clínica de crianças.

Não me parece que a psicanálise avance em relação à psicologia e à neurologia negando o desenvolvimento ou desinteressando-se pelo mesmo, mas, ao contrário, se veria amplamente enriquecida em sua teoria e em sua clínica se levasse em conta as investigações de outras disciplinas a esse respeito, e, por 
sua vez, me parece que à psicanálise corresponde contribuir com algumas explicações fundamentais, que permitem dar conta do que possibilita, condiciona e ordena o desenvolvimento 3 (1995).

\section{O QUE É O DESENVOLVIMENTO?}

No "Seminário XXI: Les non dupes errent...", Lacan diz que "o desenvolvimento seria essa viagem do nascimento à morte" e o grafa com um vetor que teria seu ponto de origem no nascimento e sua conclusão na morte.

Sobre o mesmo vetor, podemos marcar o ponto correspondente à puberdade, dizendo que, a partir desta, a estrutura do sujeito cuja vida estamos nos referindo, já definiu e modelou no real as linhas principais de sua singularidade, e que previamente a isso a estrutura se encontrava em construção.

Continua Lacan: "em qualquer ponto que se esteja desta aspirada viagem (...) a estrutura não dá seu braço a torcer e o desejo é, estritamente, sempre o mesmo". Lacan se refere, logicamente, ao indestrutível desejo freudiano. Continua dizendo que o ser surge "em um mundo no qual reina esse discurso e que tal sujeito está perfeitamente determinado enquanto a seu desejo, do começo ao fim".

Estas afirmações me parecem especialmente coerentes com o que Freud escreve em "Três ensaios...": "enquanto que, pelos processos da puberdade, fica fixada a primazia das zonas erógenas (...), tem lugar nos domínios psíquicos a descoberta do objeto, momento que vem se preparando desde a mais tenra infância. (...) A descoberta do objeto não é realmente mais que um retorno ao passado" (Freud, 1973b, 1224/5).

Mas... O que pode querer dizer que "o desejo estava perfeitamente determinado desde o começo"? Será que, por exemplo, desde antes do nascimento de um sujeito em particular já estava escrito que, ao chegar à puberdade, sua escolha iria recair sobre um objeto heterossexual - ou homossexual se fosse o caso?

Se "Três ensaios..." foi escrito para sepultar todo determinismo pseudobiológico prévio, o substituiremos agora por um determinismo supostamente estrutural? Não creio que esta tenha sido a idéia de Freud, nem de Lacan. Não creio que essa seja a leitura que convenha à psicanálise. A princípio, o determinismo da psicanálise se constrói aprés-coup, não serve para prognosticar o futuro. De qualquer maneira, o tema é muito mais sutil e complicado, e, como a clínica de crianças, em boa medida, diz respeito ao futuro, vale a pena que nos detenhamos a aprofundar esta questão. Volto a apoiar-me então em um parágrafo de Freud, ao qual já recorri em outras oportunidades:

"Teremos que prevenir-nos novamente (...) contra uma injusta censura. Pelo fato de ressaltarmos a importância das impressões infantis, acusam-nos de negar a que corresponde aos fatores congênitos (constitucionais). Esta censura tem sua origem na restrita necessidade causal dos homens, que, em franca contradição com a estrutura geral da realidade, procura satisfazer-se com um único fator causal" (Freud, 1973c, p. 1648).

Freud está falando aqui do que ele mesmo denominou "séries complementares". Entendo que a "disposição congênita, o constitucional", somente pode referir-se ao biologicamente herdado, ao orgânico, ao real do corpo que é objeto de estudo da medicina. E as "impressões infantis"? São a marca do vivido nas experiências infantis, especialmente aquelas que acontecem no 
tempo prévio à repressão edípica e que passarão a formar o acervo da repressão primária.

Dizíamos acima que o saldo das primeiras experiências infantis é, definitivamente, a marca deixada pelo Outro sobre o papel do sistema nervoso central ao cortar o objeto da pulsão, com o que poderíamos afirmar que em cada "impressão", ou seja, cada vez que um traço mnemônico é impresso, intervêm fatores causais: o orgânico por um lado (no que diz respeito à sua capacidade para registrar o ocorrido) e o significante, por outro (enquanto Outro real que escreve a partir de uma história significante prévia e, mais adiante, também enquanto Outro, o inconsciente, que começa a estar inscrito na própria criança).

Freud continua, dizendo que: "a psicanálise disse muitas coisas sobre os fatores acidentais da etiologia e muito poucas sobre os constitucionais, mas somente porque podia contribuir para os primeiros com grande quantidade de novos dados, e, em troca, não sabia nada especial sobre os últimos, exceto o já conhecido".

Quais seriam os "fatores acidentais da etiologia"? Pelo fato de estarem colocados em oposição aos constitucionais, e pelo que continua dizendo depois, não restam dúvidas de que se refere às experiências infantis, às quais atribui, então, um caráter acidental, do qual careceria o congênito.

Continua Freud: "recusamo-nos a estabelecer uma oposição fundamental entre ambas séries de fatores etiológi$\cos (\ldots) "$.

A esta altura, torna-se necessário explicitar: para Freud, "ambas séries de fatores" são as impressões infantis (às quais atribui um caráter acidental) e o constitucional (que não teria esse caráter). De minha parte - e com a conseqüente fundamentação - algumas linhas acima substituí as duas séries de fatores mencionados por Freud, por outras duas: a causa relativa ao orgânico e a causa significante (implicada esta última na experiência infantil).

Retomemos Freud, que, em seguida, acrescenta o melhor: "recusamo-nos a estabelecer uma oposição fundamental entre ambas séries de fatores etiológicos, e supomos a existência de uma colaboração regular de ambas para a produção do efeito observado. O destino de um homem é determinado pelos dois poderes - daimon e tujé - raramente, talvez nunca, por apenas um deles" (Freud, 1973c, p 1648).

Para aqueles que leram o "Seminário XI", digamos que daimon e tujé implicam os mesmos conceitos que Lacan menciona como automaton e tyché (Lacan, 1973). Tyché 


\section{REFERÊNCIAS BIBLIOGRÁFICAS}

BACHELARD, G. (1974). La formación del espiritu científico. México. Ed. Siglo XXI.

CORIAT, E. (1997). Causas e Acasos. In: Revista Estilos da Clinica. Ano II, número 3. Instituto de Psicologia - USP. Segundo semestre de 1997.

CORIAT, E. (1997). Psicanálise e clinica de bebês. Porto Alegre. Ed. Artes e Ofícios.

FREUD, S. (1973 a) "Carta 52". In: Obras Completas. Madrid. Ed. Biblioteca Nueva. [1896].

FREUD, S. (1973 b) "Tres ensayos para una teoría sexual". In: Obras completas. Madrid. Ed. Biblioteca Nueva. [1905].

FREUD, S. (1973 c) "La dinámica de la transferencia". In: Obras completas. Madrid. Ed. Biblioteca Nueva. [1912].

LACAN, J. (s/ data) Seminario XXI: Les non dupes errent. Aula 1 (inédito). Tradução de Irene Agoff de Ramos. Escuela Freudiana de Buenos Aires.

LACAN, J. (1973). Seminario XI: Los cuatro conceptos fundamentales del psicoanálisis. Buenos Aires. Ed. Paidós.

LACAN, J. (1985). "La instancia de la letra en el inconsciente". In: Escritos 1. Buenos Aires. Ed. Siglo XXI.

LEVIN, E. (1995) La infancia en escena Buenos Aires, Argentina. Ed. Nueva visión.

\section{NOTAS}

1 Trabalho apresentado no Congresso Internacional de Psicanálise e suas Conexões: Trata-se uma criança. Organizado pela Escola Lacaniana de Psicanálise - Rio de Janeiro, 19-22 de agosto de 1998.

2 JERUSALINSKY, A. e colab. (1987). Psicoanálisis en problemas del desarrollo infantil. Buenos Aires, Argentina. Ed. Nueva Visión. [O cap. III: Desarrollo: lugar y tiempo del organismo vs. Lugar y tiempo del sujeto, cujo autor é Alfredo Jerusalinsky, é reconhecido como um antecessor em relação à problemática trabalhada no presente texto.

3 No seio da equipe do centro "Dra. Lydia Coriat", Esteban Levin voltou a trazer à tona a polêmica em torno à relação entre estrutura e desenvolvimento. $O$ debate a respeito me sensibilizou para a profunda importância do tema e, de alguma maneira, o presente trabalho é efeito do que venho elaborando desde entào. Se comparamos ambos textos, o leitor poderá encontrar alguns pontos de coincidência (são anos de trabalho compartilhado!) mas em relação a outros, estruturais, notará que, decididamente, não afirmamos o mesmo. 